Canadian University Music Review

Canadian University Music Review

Revue de musique des universités canadiennes

\title{
Neo-Tonality or Neo-Atonality?: I Waited Patiently for the Lord by Gerald Bales
}

\section{Edward R. Phillips}

Numéro 4, 1983

URI : https://id.erudit.org/iderudit/1013908ar

DOI : https://doi.org/10.7202/1013908ar

Aller au sommaire du numéro

\section{Éditeur(s)}

Canadian University Music Society / Société de musique des universités canadiennes

\section{ISSN}

0710-0353 (imprimé)

2291-2436 (numérique)

Découvrir la revue

Citer cet article

Phillips, E. R. (1983). Neo-Tonality or Neo-Atonality?: I Waited Patiently for the Lord by Gerald Bales. Canadian University Music Review / Revue de musique des universités canadiennes, (4), 308-329. https://doi.org/10.7202/1013908ar

(c) Canadian University Music Society / Société de musique des universités canadiennes, 1983
Ce document est protégé par la loi sur le droit d'auteur. L'utilisation des services d'Érudit (y compris la reproduction) est assujettie à sa politique d'utilisation que vous pouvez consulter en ligne.

https://apropos.erudit.org/fr/usagers/politique-dutilisation/ 


\title{
NEO-TONALITY OR NEO-ATONALITY?: I WAITED PATIENTLY FOR THE LORD BY GERALD BALES
}

\author{
Edward R. Phillips
}

The first hearing of Gerald Bale's piece, I Waited Patiently for the Lord, exposes a conflict between the obviously tonal elements present and certain passages that seem not at all to be tonally organized. Initially, the analysis of this anthem was intended to provide not only a better understanding of the music at hand but also more general insights into the structure of music that cannot comfortably be categorized as completely tonal or atonal. However, the analysis presented below, rather than offer firm conclusions, deals with the general aspects of the investigation through the refinement of questions, with indications for further research.

In the early part of this century, music in such a stylethat is, with obviously tonal roots-was visible as part of the so-called transition between the chromaticism of the late Romantic era and the fully atonal music of later decades. This transition has become recently the focus of theoretical research; Allen Forte, for example, contributed a very detailed article on Schoenberg's creative evolution which appeared a few years ago in The Musical Quarterly (1978). However, music in this style has not been limited to the period before the First World War. More recent examples have been termed "neo-tonal" or "neo-classical." While these labels are sometimes no more than euphemisms for "anachronistic" or "inferior," they more often indicate a presupposed analytical approach to the music: that is, to analyze the piece as far as is possible in a tonal fashion and then to dismiss the more troublesome areas with simple description. Yet, this analytical approach of assuming the validity of tonality together with the verbal handwaving of such terms as "color 
chord," "slight alteration," or "extended passing motion" can be pejorative even with the best intentions. For by assuming this method to be adequate, the analyst implies that any such piece is indeed an inferiorly constructed tonal piece with certain peculiarities that need to be somehow excused. Consider Example 1, the conclusion of Francis Poulenc's Christmas motet, Hodie Christus natus est.

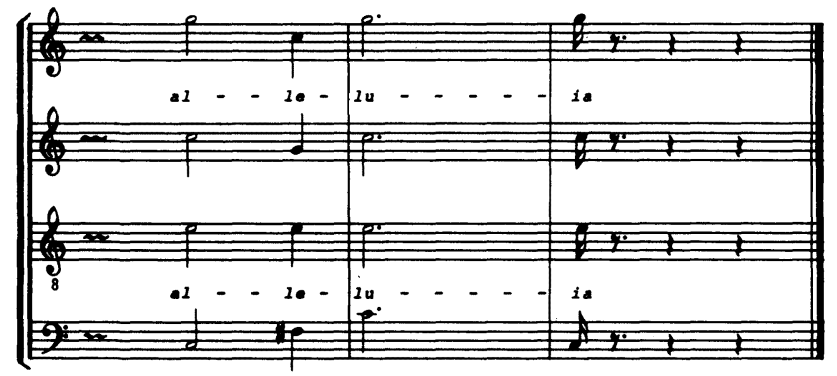

Copyright $\odot 1962$ by Salabert. Reprinted by permission.

Poulenc: Hodie Christus natus est (1952), mm. 45-47

Example 1

The bass motion, C-F sharp-C, sorely tempts any analyst to describe this event as a "sort-of-plagal-cadence-done-up-modern"; but cannot the analyst do better than to succumb to the poverty of borrowed terms? The only excuse for using the term, "plagal," is to be able to say that this event, within the organizational system of the piece, functions in a way analogous to a plagal cadence in tonal music; yet, to be able to use this analogy, the new organizational system must be determined!

This article does not pretend to present any complete theoretical system for such music; however, it does demonstrate what structures can be revealed by the application of set theoretical analysis to Bales's piece. Passing reference to tonal relationships that occur in the piece are made below, without detailed analysis, as they are more obvious.

It is first necessary to summarize the essential points of set theoretical analysis. ${ }^{1}$ The most basic notion is that music can be segmented into groups, or sets, of distinct pitches. (The most relevant sets are those of cardinality 3 through 9 -that is, with three to nine elements; octave equivalence is assumed.) Pitch class $\mathrm{C}(\mathrm{do})$ is represented by the integer 0 ; other pitch classes are represented by integers which reflect their distance, 
in semitones, from C. Given the enormous number of groups of pitches which can be found in music, there must obviously be some method of reducing the universe of sets to a small number of prototypes. That the theory considers sets as equivalent if they contain the same elements regardless of the order in which the elements appear accomplishes a substantial reduction. (That is, the set $[0,1,2]$ is equivalent to $[1,0,2],[2,0,1]$, and so on.) Further, and somewhat less obvious, reduction of the number of sets is accomplished through the operations of transposition and inversion. Briefly, if given two sets, A and B (as in Ex. 2a), $A$ is said to be equivalent to $B$ if and only if by transposing $A$ or by inverting and transposing $\mathrm{A}$ one can obtain $\mathrm{B}$. That is, A and $B$ are effectively two forms of the same set. By such a system of equivalences, the possible number of three-note sets is reduced to twelve, of tetrachords to twenty-nine, of pentachords to thirty-eight, and of hexachords to fifty. Of particular compositional interest are those subsets which remain invariant after transposition or inversion followed by transposition. Invariant subsets are those that are common to both forms of the larger sets. Consult Example 2b, which shows the invariant hexachord resulting from the operation detailed in Example 2a. The original sets, $A$ and $B$, are forms of the set 7-35 while the hexachord is set $6-32 .^{2}$

Each set has certain intervallic properties: in any given form a set can produce between the various pairs of pitches a certain number of intervals - so many semitones, so many whole tones, minor thirds, major thirds, etc. (Each cardinality produces a fixed total number of intervals; further, an interval and its inversion are held to be equivalent.) As can be seen from the table in Example 2c, set 6-32 can produce one minor second, four major seconds, three minor thirds, two major thirds, five perfect fourths, and no tritones. This same information about the interval content of the set can be read from left to right in the set's interval vector, 143250. One might expect that each distinct set would have a distinct interval content and interval vector. In general, such is the case, but there are a number of pairs of sets that are not transpositionally or inversionally/ transpositionally ${ }^{3}$ equivalent but which do share an interval vector. Such sets are indicated by a $\mathrm{Z}$ immediately following the hyphen. Example $2 d$ shows one such case; 4-Z15 and 4-Z29 are distinct sets (they are, in fact, the two all-interval tetrachords) but they have the same interval content and, thus, the same interval vector. 
a) $\mathrm{A}(7-35)=[1,2,4,6,8,9,11] \quad \mathrm{B}=[1,2,4,6,7,9,11]$

$A$, inverted (about zero) $=[11,10,8,6,4,3,1]$

A, inverted, transposed

upward by 3 semitones $=[2,1,11,9,7,6,4](=B)$

$A$ is therefore equivalent to $B(7-35)$.

b) $[1,2,4,6,9,11]=6-32$

c) $6-32=[0,2,4,5,7,9]$, Interval vector $[143250]$ Intervals (in semitones):

$\begin{array}{cccccc}1(11) & 2(10) & 3(9) & 4(8) & 5(7) & 6 \\ 4-5 & 0-2 & 2-5 & 0-4 & 0-5 & - \\ & 2-4 & 4-7 & 5-9 & 2-7 & \\ & 5-7 & 9-0 & & 4-9 & \\ & 7-9 & & & 7-0 & \end{array}$

9-2

d) $4-\mathrm{Z} 15=[0,1,4,6],[111111]$

$4-\mathrm{Z} 29=[0,1,3,7],[111111]$

Example 2

Another important relationship between sets is that of complementation. Given a set $A$, its literal complement, $A^{\prime}$, is defined as that set which contains the remaining notes of the twelve-tone universe. As can be seen from Example 3, the contents of $A$ and $A^{\prime}$ do not coincide. (In the case of hexachords, Z-related pairs are complementary while the remaining hexachords are self-complementary.) However, if $\mathrm{A}$ is inverted and transposed three semitones, its new (but equivalent) form is contained in the original form of $\mathrm{A}^{\prime}$ as a subset. Thus while no set can contain its literal complement, the operations of transposition and inversion followed by transposition make it possible for a set to contain at least one form of its complement. As is demonstrated below, this relationship between a set and a form of its complement that can be imbedded in the set has important compositional ramifications.

$A(4-27)=[0,2,5,8] \quad A^{\prime}(8-27)=[1,3,4,6,7,9,10,11]$

$A$, inverted and transposed upward 3 semitones $=[3,1,10,7]$

Example 3

The possibility of the inclusion of one set within another permits the definition of yet another important relationship between sets. Given any set, there are a certain number of sets 
of different cardinalities which are either supersets or subsets of the given set-which either include or are included in the given set. The coherence of a composition or part of a composition can be measured, in part, by the extent to which individual sets are connected by this inclusion relation. The relationship of inclusion defines families of sets related in two ways. The first "kinship" is specified in Example 4a: Given two sets, S and $\mathrm{T}$, and their complements, the set $\mathrm{S}$ and its complement $\mathrm{S}^{\prime}$ are a member of the K complex about the sets $T / T^{\prime}$ if and only if $S$ is contained in or contains $\mathrm{T}, \mathrm{OR} \mathrm{S}$ is contained in or contains $\mathrm{T}^{\prime}$. As complicated as this rule appears, it is not a very fine filter, for only one subset or superset relationship is necessary for membership in the complex. In other words, a K complex about a set resembles more a clan than a family. More restrictive is the definition of a $\mathrm{Kh}$ complex (Ex. 4b); this definition differs from that for $\mathrm{K}$ complexes in only one particular: the logical $O R$ is replaced by the logical $A N D$. But since both subset or superset conditions must now be satisfied, membership in a $\mathrm{Kh}$ complex is a much more exclusive affair.
a) $S / S^{\prime} \in K\left(T, T^{\prime}\right)$ iff $S \supset T \mid S \rtimes T^{\prime}$
b) $S^{\prime} S^{\prime} \in K h\left(T^{\prime}, T^{\prime}\right)$ iff $S \supset T^{T} \& S \supset T^{\prime}$

\section{Example 4}

Finally, in order to compare sets of the same cardinality, Forte defines four similarity relations (Ex. 5). The first is $\mathrm{Rp}$ which means simply that two sets of cardinality $n$ share a common subset of cardinality n-1. In Example 5a, it can be seen that sets 5-19 and 5-20 share at least one common subset, $(0,1,3,7)$, which is $4-Z 29$. This particular similarity relation is not very restrictive and is significant mainly when it appears in conjunction with one of the other similarity relations. The remaining such relations are based on the interval vector and thus compare the interval content of the two sets. The relation $R_{0}$ occurs when two sets have no vector entries in common; two such sets, 4-2 and 4-13, are shown in Example 5b-nowhere do the vectors correspond. Thus, the two sets have minimal similarity with respect to interval content. The relation $R_{2}$ occurs with the opposite situation: maximal similarity with respect to vector entries. In Example 5c, one can compare the vectors of 5-10 and 5-Z12 where the maximum number of entries, 4, correspond. ${ }^{4}$ 
Further, the relation $R_{1}$ is said to exist if between two vectors, four entries correspond and the remaining two entries interchange. Example 5d shows sets 4-2 and 4-3 which share four vector entries; the digits for the remaining two entries exchange places within the vectors.
a) $5-19=[0,1,3,6,7]$
Common subset $=[0,1,3,7]=4-Z 29 \quad R_{p}$
$5-20=[0,1,3,7,8]$
b) $4-2=[0,1,2,4],[221100]$
$4-13=[0,1,3,6],[112011]$
$\mathbf{R}_{\mathbf{o}}$
c) $5-10=[0,1,3,4,6],[223111]$
$5-\mathrm{Z} 12=[0,1,3,5,6],[222121] \quad R_{2}$
d) $4-2=[0,1,2,4],[221100]$
$4-3=[0,1,3,4],[212100]$
$\mathrm{R}_{1}$

Example 5

Such a brief summary as the foregoing does violence to a complicated theory, but the illustration of some of these relationships by examples drawn from Bales's piece will aid the reader's understanding.

The opening measures evoke quite strongly $\mathrm{C}$ sharp minor and are, indeed, the most placidly tonal of the piece. Nevertheless, it is here that the important sets are enunciated, eased into the listener's consciousness by the tonal setting.

For example, the triplet motive and its accompaniment beginning in the second half of measure 3 and extending into measure 4 make up the hexachord 6-33; the remainder of measure 4 and all of measure 5-that is, the expanded repetition of the motive-constitute 6-32. These two hexachords, of very similar intervallic content, are the two most important six-note sets of the piece. The first hexachord is exposed in the space of a measure; that the second requires a segmentation which sees the motive extended to a measure and a half has an aural justification: the melody is so constructed that while there is a sense of momentary completion on the $C$ sharp of measure 4 , beat two, the next triplet initiates a melodic curve that because of the repetition of B-A in the melody and the stationary accompaniment does not seem complete until the end of measure 5. 
The natural divisions of the melodic line also describe an interesting set structure. The first two gestures, despite their difference in detail, are both 4-11, a tetrachord prominent throughout the piece, especially in the a cappella section. The second triplet motion and its conclusion produce 5-35, the complement of the major/descending minor heptachord; its occurence is fortuitous since the penultimate measure of the page taken in its entirety is the set 7-35 with 5-27 (the opening set of the piece) and 6-33 imbedded in it. The only possible interpretation of this measure as a major scale is a $G$ major, and while these last two measures form a cadence of sorts in $C$ major, there is no real attempt to suggest in measure 7 a tonicization of $G$.

One might with some justification inquire at this point why any atonal exercise at all be performed on this page of music since it might be simpler just to describe these measures as a move from $\mathrm{C}$ sharp minor to $\mathrm{C}$ major. To this question, one must reply with other questions to which appear no satisfactory answers: Why move from $\mathrm{C}$ sharp minor to $\mathrm{C}$ major? There must be a structural justification for this motion, for art music does not wander aimlessly through the spectrum of keys. Yet the traditional relationships of tonality do not suffice to explain the change of tonal center. Further, how is this change accomplished-by an "extended passing motion" in the pedal part in measures 6 through 8 ?

Furthermore, it must also be noted that for all the appearance of a solid statement of $C$ major in measures 8 and 9, measure 9 is not so simple as it might appear. The entire bar forms the same 7-35 as measure 7 which, if interpreted as a major scale, must again be that of $G$ in spite of the sustained $C-G$ fifth in the bass. ${ }^{5}$ The first three beats of the measure constitute 6-33; the right hand parts each produce 4-11 with a perhaps significant invariant pitch of $\mathrm{G}$; the last three beats of both upper parts taken together are also 4-11; the final chord in the hands is 5-35, an imbedded complement.

Finally, the motion to a sonority anchored on $\mathrm{G}$ in measures 10 and 11 may appear to relate to $C$ major, too; but the "added notes," the "independent details," do produce 6-33 again overall.

With measures 12 and 13 there is no doubt that an attempt at tonal analysis is inappropriate. The composer himself hears this brief section as atonal; and, indeed, it is here that sets more typical of better known atonal music appear. So complete is the aural contrast that it is not apparent how this interlude 
might have any structural connection with the more tonally tinged parts of the piece. Nonetheless, the connection is present in several ways as is shown below.

In measures 12 and 13 , the sonorities struck over G sharp and $F$ sharp in the pedal are the same hexachord, 6-Z19; those sounded over B and A are 6-30. This relationship is, in fact, quite easily heard as the two forms of each set are related by a simple transposition and are voiced to sound as a sequence. More important, however, is the fact that 6-Z19 and 6-30 are in minimal similarity with respect to interval content while the verticals which result in measure 13 on beats two and four from the passing motion in the alto voice are two Z-related hexachords (6-Z29 and 6-Z50) which, of course, have identical interval content. That is, by changing one pitch in two maximally dissimilar hexachords, the composer has created two six-note sets with precisely the opposite intervallic property. What is more, he has done so while maintaining the basic interval patterns of the verticals in question. In Example 6, the columns of integers represent the intervals (expressed in semitones as interval classes) between adjacent pitches in the six verticals under consideration. Note that the motion from 6-Z19 to 6-Z29 and from 6-30 to 6-Z50 does not change the intervals within each pair of hexachords, it merely rearranges them. These are sophisticated atonal techniques indeed.

\begin{tabular}{|c|c|c|c|c|c|}
\hline & 2 & $3 r$ & 5 & $2 \pi$ & \\
\hline 5 & 3 & 5 & $y_{3}$ & $3^{2}$ & 2 \\
\hline 3 & 3 & 3 & 3 & 3 & 3 \\
\hline 4 & 3 & 4 & 4 & 3 & \\
\hline 5 & 5 & 5 & 5 & 5 & \\
\hline & $\begin{array}{l}\tilde{D} \\
\text { bे } \\
\dot{b}\end{array}$ & $\begin{array}{l}\vec{N} \\
\dot{b}\end{array}$ & $\begin{array}{l}\text { क्ञ } \\
\text { N } \\
\text { b }\end{array}$ & $\begin{array}{l}\bar{p} \\
\text { b } \\
\text { b }\end{array}$ & \\
\hline
\end{tabular}

Example 6

It remains to demonstrate the methods by which these two measures are connected to the rest of the piece. Bales has indicated that he intends the quarter-note passing motion in the alto voice of measure 13 as a reference to the triplet motive at the beginning. There are also connections that can be described by reference to sets as is shown in Example 7. 


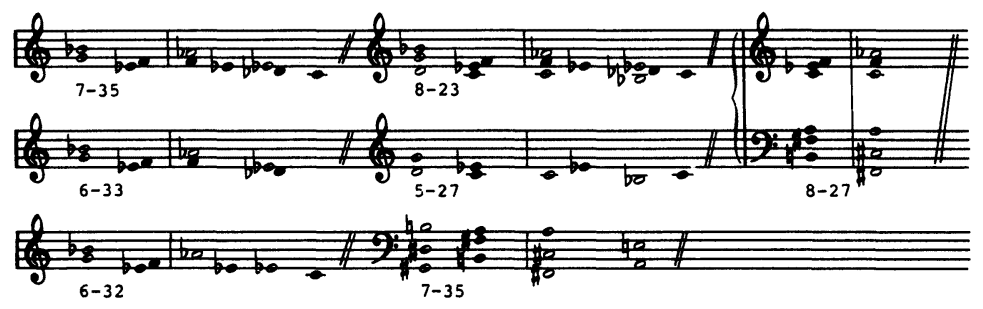

Example 7

Specifically, the upper two voices taken together in measures 12 and 13 form 7-35; if the quarter notes in the alto voice on beats two and four of measure 13 are omitted from this collection, 6-33 is produced; if, instead, those on beats one and three are omitted, 6-32 is produced. The three upper parts form 8-23, the closing set of the piece. The lower two of the upper three parts (omitting the first and third alto notes of measure 13) form 5-27, the opening set of the piece. Another form of 7-35 can be found in the lower voices; the last vertical of measure 12 and the first of measure 13 form 8-27, the first eight-note set of the following section. ${ }^{6}$ In short, this section does expose sets that appear nowhere else in the piece and that are much more typical of atonal structures than are the ones found elsewhere. These new sets appear as the aurally prominent verticals in these two measures; but, at the same time, they are subtly interwoven with the sets previously exposed in a quasi-tonal context.

As a final example of the bond between these two measures and the rest of the music, consider measures 14 through 16 which begin the next section. The melody is evidently an evocation of the opening melodic line; $C$ sharp minor is again the apparent tonal center. However, there is a small but important difference: the E sharp which produces that to which the composer refers as a kind of bi-modality. The much more important product of this E sharp is the aggregate set of these few measures: 6-Z19. That this sonority should be interpreted as a connection between the "atonal" measures (12 and 13) and the following measures which reassert the opening material is supported by the fact that this hexachord appears nowhere again in the piece.

This connective beginning to the section from measure 14 to measure 22 signals a riot of significant set interaction. Some sets, particularly such tetrachords as 4-8 and 4-16, are peculiar to this section but relate strongly not only to each other but also to other tetrachords found elsewhere in the piece (see Table 
I). Other sets, such as 4-11, which are important to the structure throughout the piece also appear frequently.

Similarity relations and complementation continue to be important organizational factors-frequently in conjunction. Within the voice parts of measures 16 and 17 are interlocking statements of 5-24 and 5-34. At the same time, the voice parts of the second eighth of measure 17 form 5-24 when taken with the upper three notes of the accompaniment, while the voice parts of the last eighth of the measure form 5-34 with the same notes of the sustained chord. More important than these intersections of horizontal and vertical are the facts that 5-24 and 5-34 are in relation $R_{2} R_{p}$ (see Table IV) and that 5-34 is complemented by 7-34 (the voice parts of measures 16 and 17 taken in their entirety). ${ }^{7}$

Consider, as well, measures 18 through 20. The entire passage is $8-23$, a set which was mentioned in connection with the previous section. The final vertical of measure 18 and the second of measure 19 are sets 7-35 and 7-23, respectively. As indicated, they both contain their complements; in addition, they are strongly similar sets in relation $R_{2} R_{p}$. That they are not adjacent verticals might weaken the connection if the intervening set were not the prominent 5-27.

The close of this section is even more tightly organized. Measure 21 and the first three beats of measure 22 form 7-35. The bottom two parts in rising fifths produce two interlocking forms of 4-23, the complement of the 8-23 just before; the union of these two tetrachords is 6-32. The voice parts and the upper three parts of the right hand each form a version of 5-27. Measure 21 taken as a unit forms 6-33 while the organ part of this measure is $5-35$, the complement of the global set. Finally, the voices which actually articulate the third beat of measure 21 taken with the last sonority of the section again form 6-32. Not to repeat the upper three voices of the accompaniment on beat three of measure 21 was thus an important compositional decision.

The subsequent measures through the third beat of measure 30 continue this coherent structure of which the following is but one example. ${ }^{8}$ Measure 28 and beat one of measure 29 form, as indicated, 6-32, as do the two sonorities following; the invariant subset is 5-35. Measure 29 as a whole presents 7-35 (the complement of the invariant subset) as do the first two chords of measure 30; the invariant subset here is 6-32!

The piece closes with the large set $8-23$, as already mentioned, in which are imbedded many more significant examples of set 
usage. ${ }^{9}$ Within this large set are contained two forms of 6-32, one of which is also contained in an expression of 7-35. The invariant subset between the two forms of the hexachord is again 5-35, the complement of the seven-note set. The other important hexachord, 6-33, occurs as the lower three parts of measure 33.

Tables II through IV represent the $\mathrm{Kh}$ and similarity relations for the entire piece. The reader can easily convince himself/ herself that these aspects of the piece also indicate a coherent organization. Apparent lapses in connectedness (represented by blank spots in these tables) are most often attributable to sets, particularly those of Section III, of only local significance. (The reader is referred again to Table I.) Briefly, it can be seen from the $\mathrm{Kh}$ table (Table II) that 6-32 and 6-33 are the central or "nexus sets" (after Forte) of the piece. Following Forte's theory, these two sets of the same cardinality must be related by being in $\mathrm{Kh}$ relation with a set of differing cardinality; the most likely candidate is 5-35(7-35), a set compositionally related to the two hexachords by its prominence throughout the piece, its proximity to the hexachords, and, indeed, its invariant subset (and superset) relationship with 6-32. It should be emphasized that 6-32 and 6-33 are in $R_{2} R_{p}$ relation, as well.

What, then, is to be done with this music? It is not part of a historical transition from one system to another as one might consider the early works of Schoenberg. Given its complex use of atonal techniques, this piece cannot be condemned as anachronistic (that is, neo-tonal); nor can it be considered as an inferior imitation of atonal music (that is, neo-atonal) simply because the sets chosen are not those most typical of the composers of the Viennese school ${ }^{10}$ or because certain atonal techniques such as set complementation are not consistently exploited. At least, one cannot make a critical judgment on the basis of these criteria without also condemning the music of many others. (The chord over the F sharp in Ex. 1 is $4-\mathrm{Z} 29$, for instance.)

More disturbing than trying to place this music in a historical perspective or trying to find a comprehensive tonal system that describes it are the implications that this analysis presents for ideas of transition between theoretical systems. When Schoenberg's early works are considered, the perplexing notion that the music might be organized according to two contradictory systems can be excused, perhaps, by the very real possibility that this particular repertoire is experimental, in motion be- 
tween two points. When, however, music of a composer's maturity seems to partake of two such systems, the theoretical contradiction becomes real. Bi-tonality and bi-modality (as distinct from modal mixture), unfortunately accepted terms for music not otherwise understood, are also self-contradictory classifications. The idea of a piece's being organized around two keys at once (around two distinct I-V-I axes) is about as tenable a concept as bigamy!

What can a theorist then make of a musical structure that seems to be both tonal and atonal? It is all too easy to maintain the historical model which describes the movement from tonality to atonality as a slide greased by slippery chromaticism, but this idea of gradual erosion of the tonal system-while an adequate description of certain elements of the musical surfaceneatly avoids speculation as to when during this slippery slide the harmonic axis of I-V-I was abandoned as basic structure. While one can document-as Forte has done so well in his article on Schoenberg's early works - the growth of atonal structures in works that can, from a historical point of view, at least, be defended as transitional, the question as to the nature of the background structure in these pieces that are neither fish nor fowl remains.

The notion that there was, during the sixteenth and seventeenth centuries, a similar gradual motion from modality to tonality via musica ficta has already been questioned. Indeed, some theorists believe that tonality had deeper and more definite roots in early music than has been suggested by the traditional historical explanation. It is possible that the relationship between tonality and atonality is just as close and that scholars are only now beginning to be sufficiently removed from the first years of this century to question the model of gradual change just cited and to be able to discover, therefore, what that relationship between the two organizational systems of tonality and atonality is. 
Sets by Section

IA (mm. 1-6)

B (m7)

3-11

4-11, 4-14* $4-20,4-22,4-26,4-\mathrm{Z} 29$

$5-27,5-35 / 7-35^{*}$

6-Z25, 6-Z26* ${ }^{*}, 6-32,6-33$

* B only

II (mm. 8-11)

3-7, 3-11

4-10, 4-11, 4-20, 4-22, 4-26, 4-27

$5-25,5-35 / 7-35$

6-33

III (mm. 12-13)

$3-6,3-10 / 9-10,3-11$

4-12, 4-13, 4-17, 4-18, 4-19, 4-26, 4-27/8-27, 4-28

5-Z18, 5-21, 5-22, 5-25, 5-27, 5-31/7-31, 5-32/7-32

6-Z19, 6-Z29/6-Z50, 6-30, 6-32, 6-33

7-23, 7-34, 7-35

IV (mm. 14-22b3; "I waited patiently for the Lord and He inclined unto me and heard my calling")

3-11

4-8, 4-11, 4-14, 4-16, 4-17, 4-20, 4-21, 4-22, 4-23/8-23, 4-26, 4-27/8-27, 4-Z29

$5-16,5-20,5-21,5-23 / 7-23,5-24,5-27,5-32,5-34 / 7-34$, $5-35 / 7-35$

6-Z10, 6-Z19, 6-Z26, 6-32, 6-33, 6-Z46
VA (mm. 22b4-26b2; "The Lord shall preserve thee from all evil.") 3-11

4-14, 4-20, 4-23, 4-26, 4-27

$5-23,5-24,5-27,5-35 / 7-35$

6-Z25, 6-32, 6-33

VB (mm. 26b3-30b3; "The Lord shall preserve thy going out and thy coming in....")

3-11

4-14, 4-20, 4-23/8-23, 4-26

$5-23,5-35 / 7-35$

6-Z25, 6-Z26, 6-32, 6-33

VC (mm. 30b4-35; “... from this time forth for ever more.")

3-11

4-11, 4-20, 4-22, 4-26, 4-27

5-23, 5-24, 5-27, 5-32, 5-34, 5-35/7-35

6-Z26, 6-32, 6-33

8-23

Sets occuring in Sections $\mathrm{I}-\mathrm{V}$ 3-11 (triad); 4-26; 6-32, 6-33; 7-35

Sets occurring in Section I, II, IV, V

$3-11 ; 4-11,4-20,4-22,4-26 ; 5-35 ; 6-32,6-33 ; 7-35$

Sets occurring only in Section III

3-6, 3-10; 4-12, 4-13, 4-17, 4-18, 4-19, 4-28; 5-Z18, 5-22, 5-31; 6-Z29/6-Z50, 6-30; 7-31 (The hexachord, 6-Z19, occurs in both Sections III and IV but in IV as a connective device only.)

Sets occurring in only one of Sections I, II, IV, or V

3-7(II); 4-8(IV), 4-10(II), 4-16(IV), 4-21(IV); 5-16(IV), 5-20(IV),
5-21(IV); 6-Z10(IV), 6-Z46(IV)

Table I 


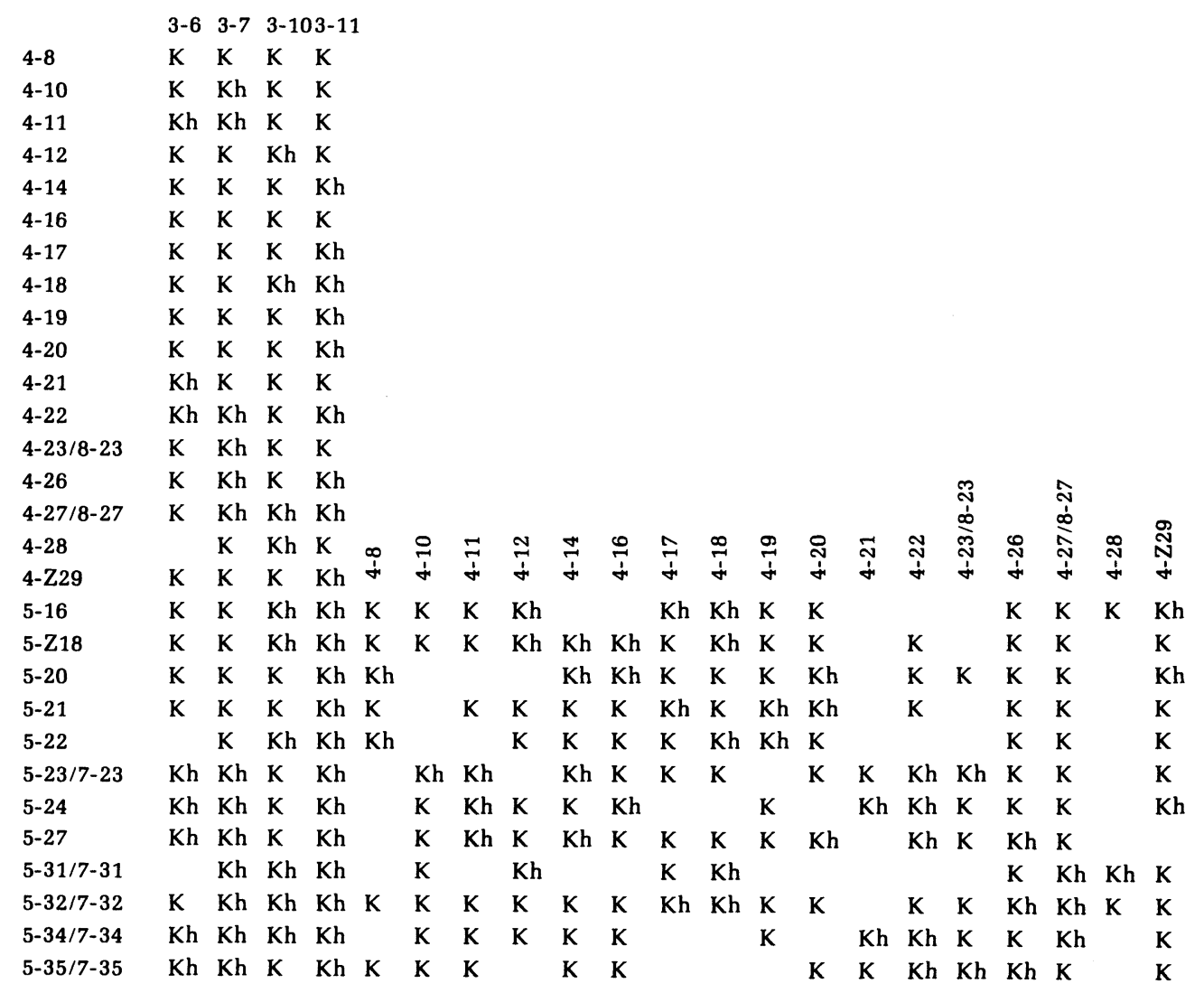




\begin{tabular}{|c|c|c|c|c|c|c|c|c|c|c|c|c|c|c|c|c|c|c|c|c|c|c|c|c|c|c|c|c|c|}
\hline 6-Z10 & $\mathrm{Kh}$ & $\mathrm{Kh}$ & $\mathrm{Kh}$ & $\mathrm{Kh}$ & & $\mathrm{K}$ & $\mathrm{Kh}$ & $\mathrm{Kh}$ & $\mathrm{K}$ & $\mathrm{K}$ & $\mathrm{K}$ & $\mathbf{K}$ & $\mathrm{K}$ & & $\mathbf{K}$ & $\mathrm{K}$ & & $\mathrm{K}$ & K & $\mathrm{Kh}$ & K K & & $\mathbf{K}$ & $\mathbf{K}$ & & & & & ** \\
\hline 6-Z19 & & $\mathrm{K}$ & $\mathrm{Kh}$ & $\mathrm{Kh}$ & $\mathrm{Kh}$ & & & K & K & K & $\mathrm{Kh}$ & $\mathrm{Kh}$ & $\mathrm{Kh}$ & $\mathrm{Kh}$ & & & & $\mathrm{K}$ & K & $\mathbf{K}$ & K K K Kh Kh & & & & & & $\mathrm{K}$ & & \\
\hline $6-Z 25$ & $\mathrm{Kh}$ & $\mathrm{Kh}$ & $\mathrm{Kh}$ & $\mathrm{Kh}$ & K & K & $\dot{\mathrm{K}}$ & & $\mathrm{Kh}$ & $\mathrm{Kh}$ & $\mathrm{K}$ & $\mathbf{K}$ & & K & & $\mathrm{Kh}$ & $\mathrm{Kh}$ & $\mathrm{Kh}$ & $\mathrm{Kh}$ & & K & $\mathrm{K}$ & & K & K & & K & K & \\
\hline $6-Z 26$ & $\mathrm{Kh}$ & $\mathrm{Kh}$ & & $\mathrm{Kh}$ & K & & $\mathrm{K}$ & & $\mathbf{K}$ & $\mathrm{Kh}$ & & & $K$ & $\mathrm{~K}$ & 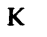 & $\mathrm{Kh}$ & K & $\mathrm{Kh}$ & & $\mathrm{K}$ & K & & K & & K & & & $\mathrm{K}$ & ** \\
\hline $6-Z 29 / 6-Z 50$ & & $\mathrm{Kh}$ & $\mathrm{Kh}$ & $\mathrm{Kh}$ & & K & & K & $\mathbf{K}$ & $\mathrm{K}$ & $\mathbf{K}$ & $\mathrm{Kh}$ & & & & & K & K & $\mathrm{Kh} \mathrm{K}$ & $\mathrm{K}$ & $\mathrm{K}$ & & & $\mathrm{K}$ & & $\mathrm{K}$ & $\mathrm{K}$ & & ** \\
\hline 6-30 & & $\mathrm{Kh}$ & $\mathrm{Kh}$ & $\mathrm{Kh}$ & & & & $\mathrm{Kh}$ & & & & $\mathrm{Kh}$ & & & & & & & $\mathrm{Kh} \mathrm{Kh}$ & $\mathrm{Kh}$ & & & & & & $\mathrm{Kh}$ & & & \\
\hline 6-32 & $\mathrm{Kh}$ & $\mathrm{Kh}$ & & $\mathrm{Kh}$ & & $\mathrm{Kh}$ & $\mathrm{Kh}$ & & $\mathrm{Kh}$ & & & & & $\mathrm{Kh}$ & & $\mathrm{Kh}$ & $\mathrm{Kh}$ & $\mathrm{Kh}$ & & & & $\mathrm{Kh}$ & & & $\mathrm{Kh}$ & & & $\mathrm{Kh}$ & \\
\hline $6-33$ & $\mathbf{K h}$ & $\mathrm{Kh}$ & $\mathrm{Kh}$ & $\mathrm{Kh}$ & & $\mathrm{Kh}$ & $\mathrm{Kh}$ & & $\mathrm{Kh}$ & $\mathrm{Kh}$ & & & & & $\mathrm{Kh}$ & $\mathrm{Kh}$ & $\mathrm{Kh}$ & $\mathrm{Kh}$ & $\mathrm{Kh}$ & $\mathrm{Kh}$ & & $\mathrm{Kh}$ & $\mathrm{Kh}$ & $\mathrm{Kh}$ & & & $\mathrm{Kh}$ & $\mathrm{Kh}$ & \\
\hline 6-Z46 & $\mathrm{Kh}$ & $\mathrm{Kh}$ & $\mathrm{Kh}$ & $\mathrm{Kh}$ & & $\mathrm{K}$ & $\mathrm{Kh}$ & $\mathrm{K}$ & $\mathrm{Kh}$ & $\mathrm{K}$ & $\mathrm{K}$ & $\mathbf{K}$ & $\mathrm{K}$ & $\mathrm{K}$ & K & $\mathrm{Kh}$ & $\mathbf{K}$ & K & $\mathrm{Kh}$ & * & & $\mathrm{K}$ & & & $\mathrm{K}$ & & K K & & $\star *$ \\
\hline
\end{tabular}

* In Kh with 4-Z15.

**No pentachords in Kh complex.

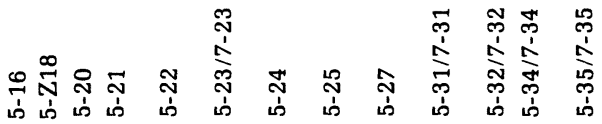


Similarity Relations, Tetrachords

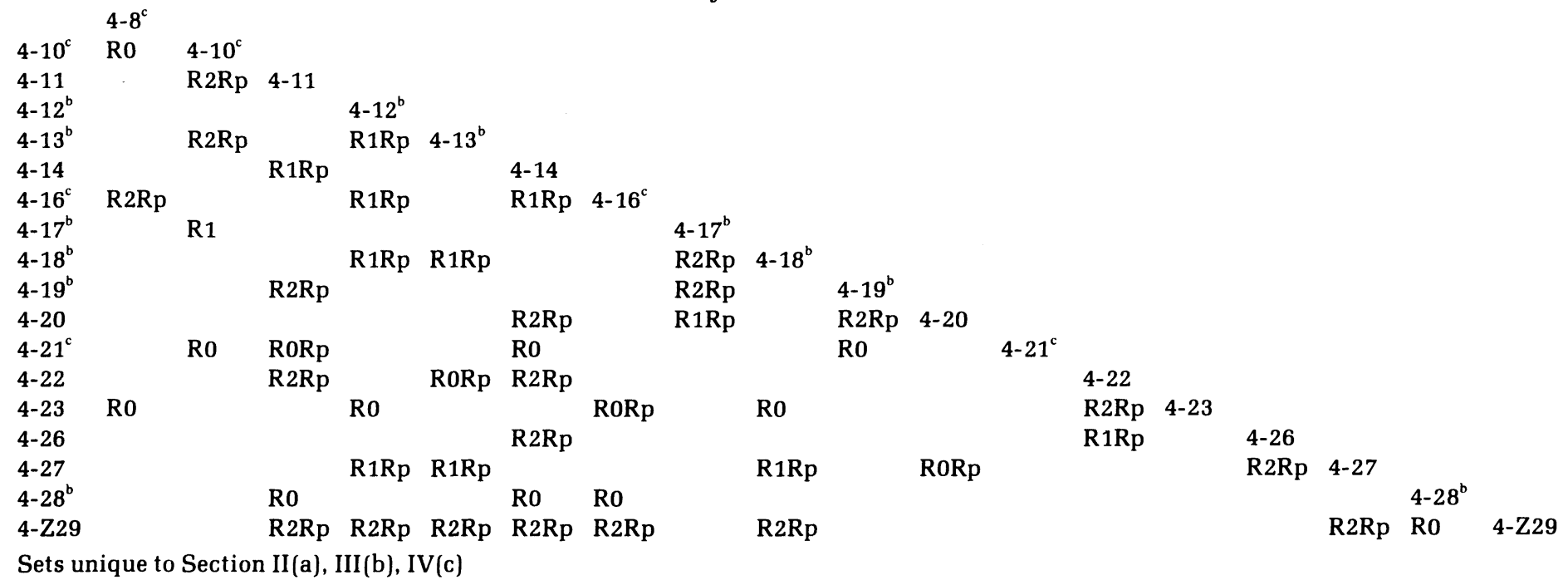

Table III 
Similarity Relations, Pentachords

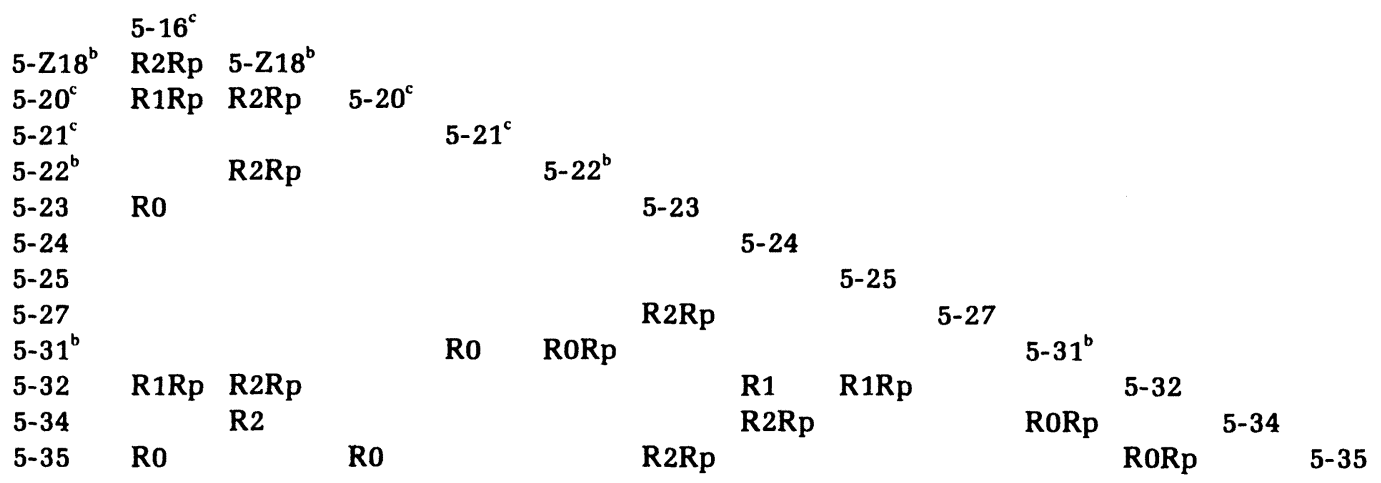

Sets unique to Section $\operatorname{II}(a), \operatorname{III}(b), \operatorname{IV}(c)$

Similarity Relations, Hexachords

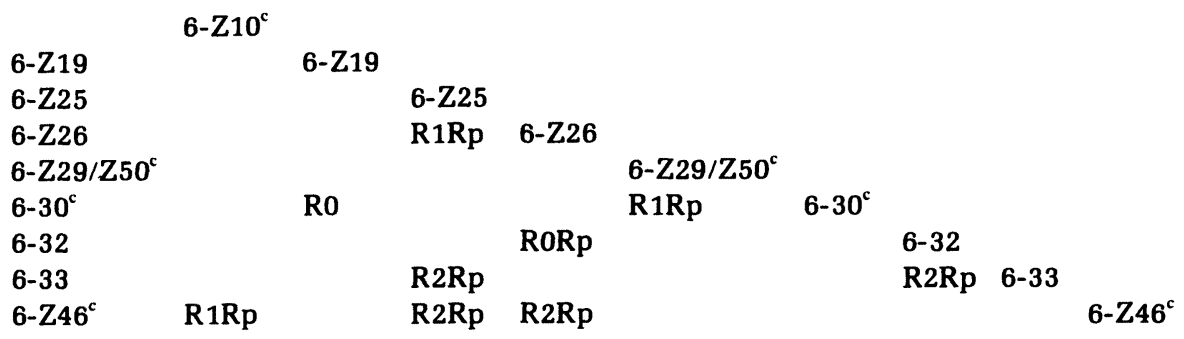

Sets unique to Section II(a), III(b), IV(c) 

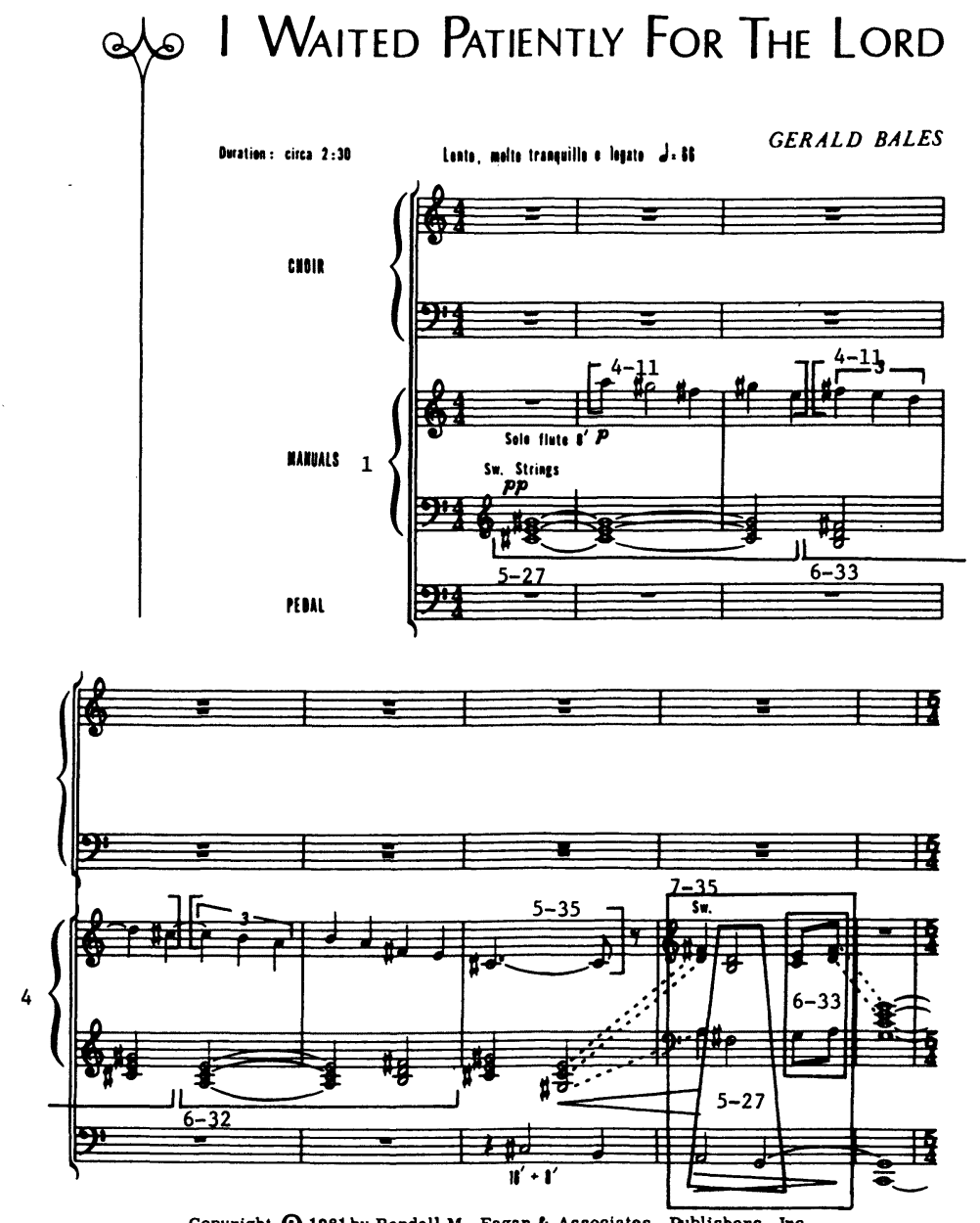

Copyright (C) 1981 by Randall M. Eagan \& Associates, Publishers, Inc. All Rights Reserved. Printed in U.S.A.

Reprinted by permission. 


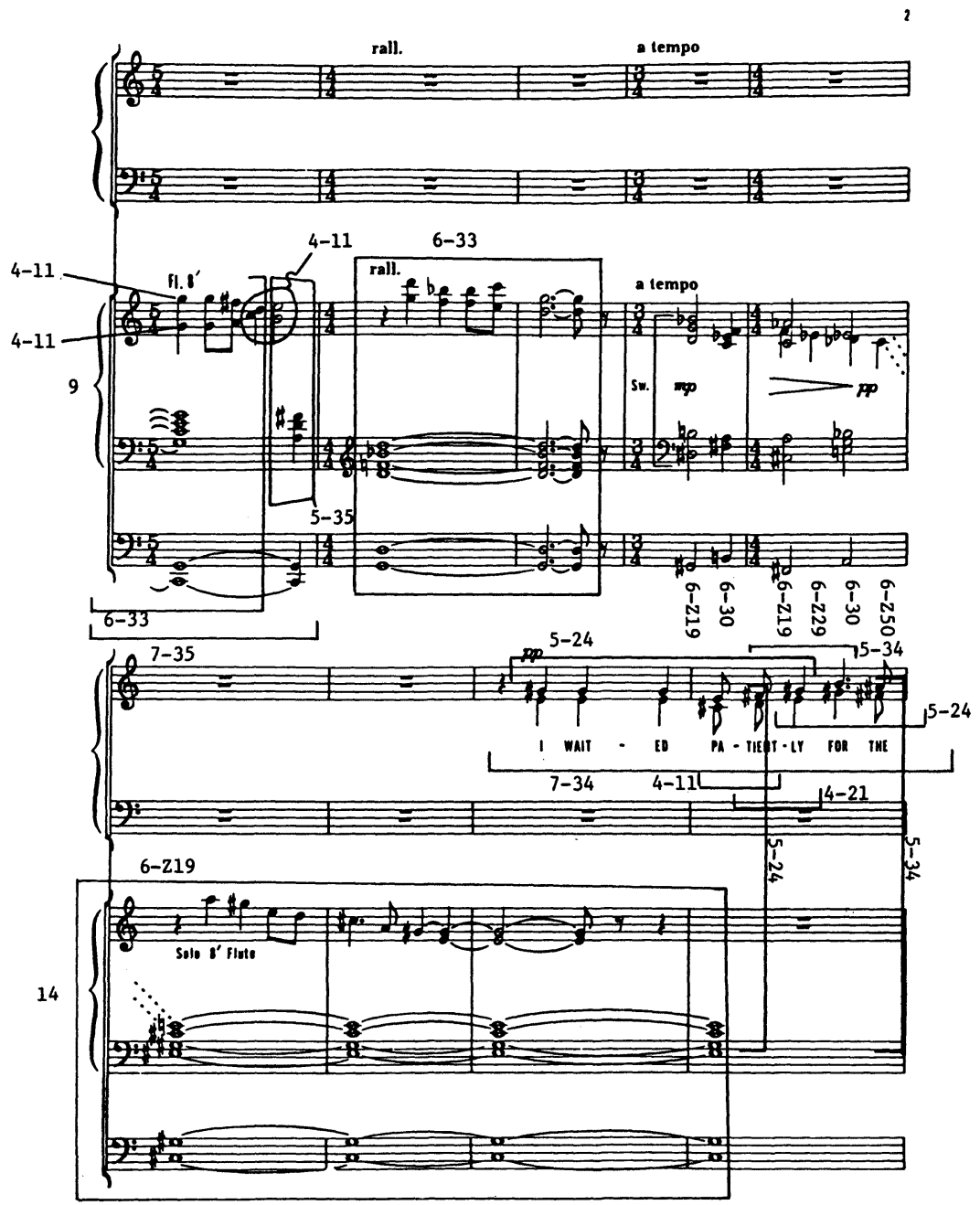



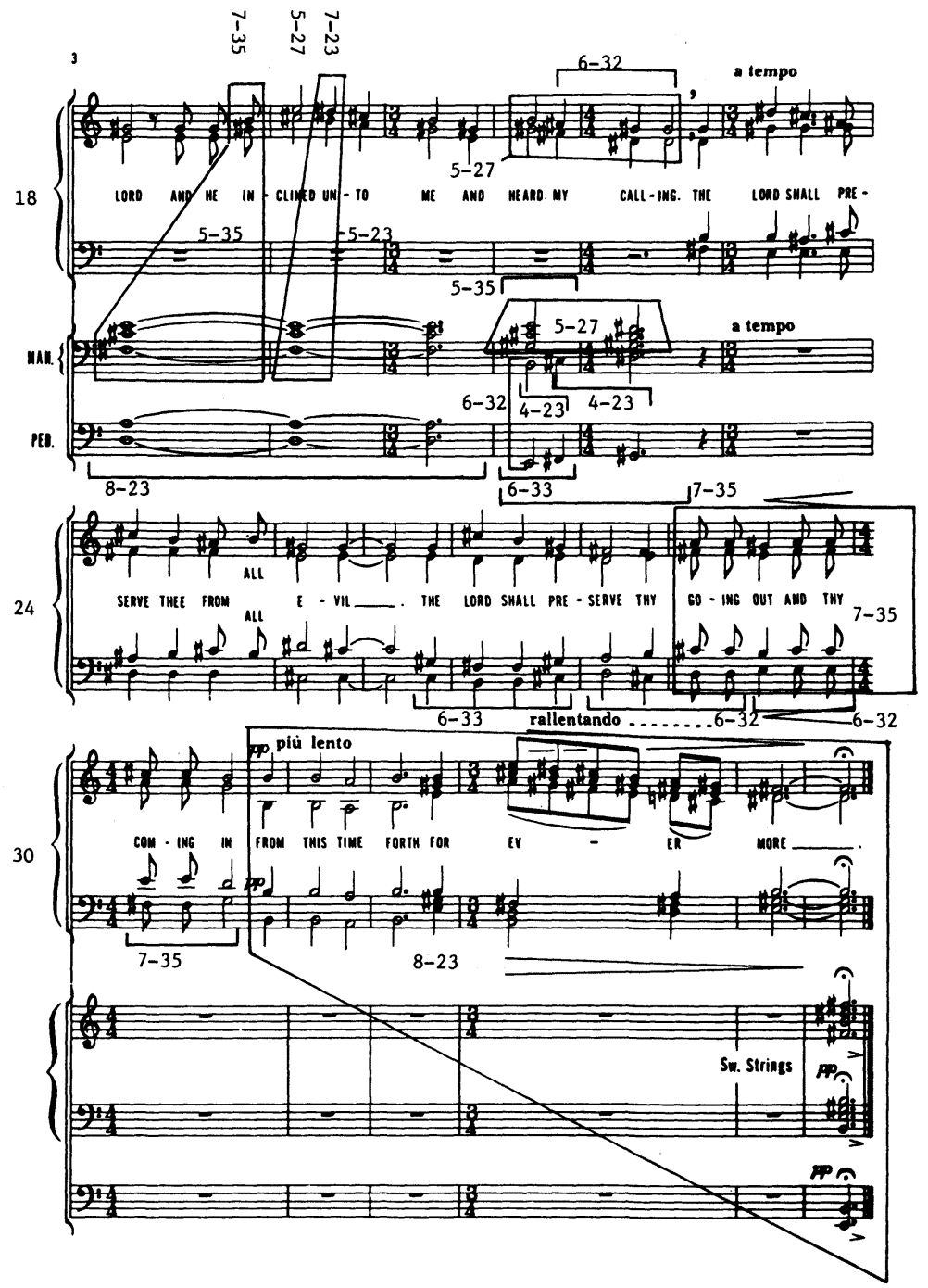


\section{NOTES}

1. This method has been developed by Allen Forte and is exposed completely in his book (1974). An excellent discussion of this theory is contained in Beach (1979).

2. The number before the hyphen indicates the cardinality of the set, and the number following the hyphen that set's position within Forte's list of possible sets (see Forte 1974: 179ff.).

3. The operation of inversion always implies a subsequent transposition if only at level zero-that is, by zero semitones or, equivalently, by the interval of the unison.

4. Since each set of a given cardinality forms the same number of intervals, no more than four vector entries can correspond without the vectors being identical, without all six entries' being identical.

5. When this article was presented at the 1982 conference of the Canadian University Music Society, Brian Ellard (then of l'Université de Sherbrooke) raised a question concerning set theory's failure to account for voicings such as the sustained fifth in measure 9. To my answer that the application of set theory to twentieth-century music is continually being made more precise, I add the following refinement. In a fully tonal piece, a prominent fifth such as that in measure 9 may produce various effects, but it will not make the piece seem any more tonal; similarly, in a convincingly atonal piece, such an interval would not make the piece any less atonal. As this exercise with Bales's piece was undertaken to show what strict atonal set theoretical analysis would reveal when applied to a piece not completely in that repertoire, neither the analysis nor the theory can be faulted for ignoring the voicing of the fifth. Where Ellard's comment makes a real contribution, however, is in its relevance to the development of a theory to account for music that is neither tonal nor atonal where such subtleties as the voicing of an interval (instrumentation, register, and resulting overtones, etc.) do become important. Such occurrences need to be explained other than as the contradictions resulting from the collision of two antithetical methods of tonal organization-tonality and atonality.

6. At the Canadian University Music Society conference, a question was also raised concerning the justification for the segmentation of the pitches just discussed. I remind the reader that such partitioning is legal within set theoretical analysis (see Forte 1974: 83ff.). Further, so far as the six vertical hexachords are concerned, the successive consideration within the verticals of the quarter notes in the alto part has a tonal analogy. That is, in a tonal context, passing tones on weak beats would be omitted from a harmonic analysis; likewise would dissonant appoggiature be disregarded in reducing the music to its basic motions. The main considerations in either such a tonal or atonal context are intervallic. 
7. Within these pentachords in strong relation are two tetrachords, 4-11 and 4-21, which are maximally dissimilar with respect to interval content (see Table III).

8. It should be mentioned here that the simple four-voice texture of the section beginning at measure 23 again presents, both horizontally and vertically, many of the prominent tetrachords of the piece.

9. This form of 8-23 is preceded by a protracted expression of the same set formed by the soprano and alto voices in measures 26 through 30.

10. Patrick Cardy (Carleton University) has suggested that it be clearly stated that individual sets are not in themselves tonal or atonal. It is, of course, the context in which the set is found and the function of its component notes that indicate a tonal or atonal application. Nevertheless, in spite of the occurrence of 7-35 (one form of which is the major scale) in certain atonal works and of 4-19 (a set found often in atonal compositions) in works of such composers as Brahms, certain sets are found more often in atonal contexts than are others. These repertoires of "atonal sets" vary from one composer to another.

\section{REFERENCES}

BEACH, D.

1979: "Pitch Structure and the Analytic Process in Atonal Music: An Interpretation of the Theory of Sets," Music Theory Spectrum, No. 1, 7-22.

FORTE, A.

1974: The Structure of Atonal Music. New Haven: Yale University Press.

1978: "Schoenberg's Creative Evolution: The Path to Atonality," The Musical Quarterly, LXIV/2, 133-76. 